\title{
Ellipsometric Characterization of Thin Films from Multicomponent Chalcogenide Glasses for Application in Modern Optical Devices
}

\author{
R. Todorov, ${ }^{1}$ J. Tasseva, ${ }^{1}$ V. Lozanova, ${ }^{1}$ A. Lalova, ${ }^{1}$ Tz. Iliev, ${ }^{2}$ and A. Paneva ${ }^{3}$ \\ ${ }^{1}$ Institute of Optical Materials and Technologies "Acad. J. Malinowski," Bulgarian Academy of Sciences, \\ Acad. G. Bonchev Street, Building 109, 1113 Sofia, Bulgaria \\ ${ }^{2}$ Geological Institute, Bulgarian Academy of Sciences, Acad. G. Bonchev Street, Building 24, 1113 Sofia, Bulgaria \\ ${ }^{3}$ Faculty of Physics, Sofia University "St. Kliment Ohridski," 5 James Boucher Avenue, 1164 Sofia, Bulgaria \\ Correspondence should be addressed to R. Todorov; rossen@iomt.bas.bg
}

Received 4 March 2013; Revised 20 May 2013; Accepted 22 May 2013

Academic Editor: R. N. P. Choudhary

Copyright (C) 2013 R. Todorov et al. This is an open access article distributed under the Creative Commons Attribution License, which permits unrestricted use, distribution, and reproduction in any medium, provided the original work is properly cited.

\begin{abstract}
A review is given on the application of the reflectance ellipsometry for optical characterization of bulk materials and thin films with thickness between $\lambda / 20$ and $2 \lambda$ (at $\lambda=632.8 \mathrm{~nm}$ ). The knowledge of the optical constants (refractive index, $n$, and extinction coefficient, $k$ ) of thin films is of a great importance from the point of view of modelling and controlling the manufacture of various optical elements, such as waveguides, diffraction gratings, and microlenses. The presented results concern the optical properties of thin films from multicomponent chalcogenide glasses on the base of $\mathrm{As}_{2} \mathrm{~S}_{3}$ and $\mathrm{GeS}_{2}$ determined by multiple-angleof-incidence ellipsometry and regarded as a function of the composition and thickness. The homogeneity of the films is verified by applying single-angle calculations at different angles. Due to decomposition of the bulk glass during thermal evaporation, an optical inhomogeneity of the thin As (Ge)-S-Bi(Tl) films is observed. The profile of $n$ in depth of thin As-S-Tl (Bi) films was investigated by evaporation of discrete layers. It is demonstrated that homogenous layers from the previous compounds with controlled composition can be deposited by coevaporation of $\mathrm{As}_{2} \mathrm{~S}_{3}$ and metals or their compounds $\left(\mathrm{Bi}, \mathrm{Tl}, \mathrm{In}_{2} \mathrm{~S}_{3}\right)$.
\end{abstract}

\section{Introduction}

The optical constants of the thin films are commonly determined by methods such as spectrophotometry, prism-coupling technique, and ellipsometry. The ellipsometric methods are fast, nondestructive, highly sensitive to the presence of surface inclusions and provide higher accuracy for determination of the refractive index and thickness of thin layers in comparison with the spectrophotometric methods [1-4]. Currently various forms of ellipsometry exist and are applied for investigation of the physical properties of thin films [3]. The most common among these methods are the spectral ellipsometry and multiple-angle-of-incidence ellipsometry [5]. Spectral ellipsometry includes measurement and analysis of the complex reflection ratio in wide range of wavelengths at a fixed angle of light incidence. The method provides information for the optical response functions (complex refractive index, $\widehat{n}$, or complex permittivity, $\widehat{\varepsilon}$ ) [6]. The main problem of the spectral forms of ellipsometry is the selection of an appropriate dispersion model for description of the optical constants [6]. Single-wavelength ellipsometry offers an advantage in this respect since it does not require a dispersion law and enables the in situ control of the process of thin film deposition [5].

Chalcogenide glasses exhibit transmittance in wide spectral range $(1-20 \mu \mathrm{m})$, low phonon energy and bandgap, high linear and nonlinear refractive index, and high photosensitivity when illuminated by near bandgap light [7-9]. Mixing chalcogenide glasses with a relevant oxide allows extended variation of the refractive index, for example, in $\mathrm{GeO}_{2}-\mathrm{GeS}_{2}$ system [10]. The chalcogenide glasses can be deposited as thin films by a variety of techniques as thermal and flash evaporation [11, 12], spin-coating [13] and pulsed laser deposition [14]. As a result, they have found practical 
applications in manufacturing of various elements for optics in visible and infrared spectral region [15], photonics [16], and all optical processing [17] such as waveguides [18], optics amplifiers [19], diffraction gratings [20], microlenses [21], and phase-change recording media [22]. To realize all these devices and applications, one should know and be able to precisely control the optical parameters of the materials. Ellipsometric measurements have been applied for investigation of the optical properties of chalcogenide films [23-35] and of different photo-induced effects as photocrystaleization $[29,31]$, volume changes $[26,34]$, and photodissolution of metals [35]. The comparison of dispersion models for analysis of the measured spectra of ellipsometric angles ( $\Psi$ and $\Delta$ ) of thin $\mathrm{As}_{2} \mathrm{~S}_{3}$ was made in [36]. The authors [37] found that the model of Urbach-Cody-Lorentz and parameterization of the density of the electronic states model give the best fit of spectrophoptometric (transmittance and reflectance) and/or ellipsometric experimental data for thin As-S films.

This is a review paper on the optical properties and their changes after illumination of thin chalcogenide films from As-S(Se), As-S-Ge(Se), and As(Ge)-S-Tl(Bi, In) as studied by means of multiple-angle-of-incidence ellipsometry. We discuss the applicability of multiple-angle-of-incidence ellipsometry (MAI-ellipsometry) for characterization of chalcogenide layers from the above systems exclusively when irregular gradient of the refractive index is involved, resulting from compositional variation in the depth of the layers. The possibility to deposit homogeneous multicomponent chalcogenide films by coevaporation is demonstrated.

\section{Experimental Details}

Bulk glasses from the system $\mathrm{As}_{x} \mathrm{~S}_{100-x}(28 \leq x \leq 45)$, $\mathrm{As}_{x} \mathrm{Se}_{100-x}(28 \leq x \leq 50), \mathrm{Ge}_{x} \mathrm{~S}_{100-x}(20 \leq x \leq 40)$, $\mathrm{As}_{40} \mathrm{~S}_{60-x} \mathrm{Se}_{x}(0 \leq x \leq 60)$, and $\left(\mathrm{As}_{2} \mathrm{~S}_{3}\right)_{100-x} \mathrm{Bi}(\mathrm{Tl})_{x}(0 \leq$ $x \leq 10)$ were synthesized in a quartz ampoule from elements of purity $99,999 \%$ by the method of melt quenching [25, 26, 38]. Thin films with thickness between 30 and $1000 \mathrm{~nm}$ were deposited from a Mo or Ta boat with a preliminarily calculated amount of bulk materials for each particular thickness. The layers were deposited by thermal evaporation at deposition rates of $0.4-0.7 \mathrm{~nm} / \mathrm{s}$ on optical glass $\mathrm{BK}-7$ substrates. The films were exposed to white light (Mercury lamp, $20 \mathrm{~mW} / \mathrm{cm}^{2}$ ). The composition of the bulk samples and thin films deposited on graphite substrates was determined by scanning electron microscopy with an X-ray microanalyzer (Jeol Superprobe 733, Japan) [39]. The composition of the films from binary and ternary As-S-Se and As-S-Ge systems $[25,26]$ is close to that of the bulk samples, while it is observed that the amount of $\mathrm{Bi}$ or $\mathrm{Tl}$ in the thin $\mathrm{As}-\mathrm{S}-\mathrm{Bi}(\mathrm{Tl})$ layers is smaller compared to that in the bulk samples [39].

The ellipsometric measurements were carried out at three angles of light incidence: 45,50 , and $55^{\circ}$ using LEM$3 \mathrm{M} 1$ ellipsometer equipped with low-intensity $\mathrm{He}-\mathrm{Ne}$ laser $(\lambda=632.8 \mathrm{~nm})$. The measurements were performed at angles of incidence below the Brewster's angle in order to remove reflection from the back side of the substrate. The accuracy of determination of $\Psi$ and $\Delta$ was $0.01^{\circ}$ and $0.02^{\circ}$, respectively. The systematic errors were eliminated through averaging of the four zones measurements. The duration of each ellipsometric measurement was about $5 \mathrm{~min}$, and all measurements were carried out within 24 hours after the films deposition. Thus, the fast relaxation in selenium rich films [29] and oxidation of germanium containing films [40] would have not produced an artefact.

\section{Theory and Modelling}

Reflective ellipsometry is applied for quantitative estimation of an optical system by the so-called relative coefficient of reflectance, $\rho[1]$. The basic equation of the ellipsometry is

$$
\rho=\frac{R_{p}}{R_{s}}=\tan \Psi \cdot e^{i \Delta}
$$

where $R_{p}$ and $R_{s}$ are complex reflection coefficients for $p$ and $s$-polarization, respectively. $\tan \Psi$ is the ratio amplitude of the reflection coefficients $R_{p}$ and $R_{s}$ and $\Delta$ is the difference between their phases:

$$
\tan \Psi=\frac{r_{p}}{r_{s}}, \quad \Delta=\delta_{p}-\delta_{s},
$$

where $r_{p}$ and $r_{s}$ are the modulus of $R_{p}$ and $R_{s}$ and $\delta_{p}$ and $\delta_{s}$ are their phases. In the case of a three-phase system (ambient, thin film, substrate) (Figure 1(a)), (1) can be written as:

$$
\rho=\tan \Psi \cdot e^{i \Delta}=\frac{r_{01 p}+r_{12 p} e^{-i 2 \beta}}{1+r_{01 p} r_{12 p} e^{-i 2 \beta}} \times \frac{1+r_{01 s} r_{12 s} e^{-i 2 \beta}}{r_{01 s}+r_{12 s} e^{-i 2 \beta}}
$$

where $r_{01 p}, r_{01 s}, r_{12 p}$, and $r_{12 s}$ are the Fresnel coefficients for ambient, thin layer and thin layer, substrate boundaries, respectively, and $\beta$ is the phase thickness:

$$
\beta=2 \pi\left(\frac{d_{1}}{\lambda}\right) \widehat{n}_{1} \cos \phi_{1},
$$

where $\widehat{n}_{1}=n_{1}-i k_{1}$ is the complex refractive index of the thin layer with thickness $d . \phi$ and $\lambda$ are the angle of incidence and wavelength of the light, respectively.

A schematic model of an inhomogeneous layer is presented in Figure 1(b). In this case the Fresnel coefficients in (3) for ambient, thin layer and thin layer, substrate boundaries will include different refractive indices for the thin film, $n_{1}^{\prime}$ and $n_{2}^{\prime \prime}$, respectively [41].

In (4) for the phase thickness, $\beta$, the refractive index and angle of incidence are generalized by their averaged values, the product of which satisfies the following integral:

$$
n_{\mathrm{av}} \cos \phi_{\mathrm{av}}=\frac{1}{d} \int_{0}^{d} n(z) \cos [\phi(z)] d z
$$

Two-layer models are usually used for analysis of roughness and surface phenomena as oxidation. Rough-surface models involving ridges, pyramids, or other similar geometric forms have been used to simulate surface roughness [42]. For the selection of the most appropriate model, where no data 
TABLE 1: Optical parameters (refractive index, $n$, and thickness, $d$ ) of thin films from As-S-Bi (Tl, In) systems, determined by ellipsometric and Swanepoel's spectrophotometric methods at $\lambda=632.8 \mathrm{~nm}$. The composition of the thin films determined by X-ray microanalysis is given in parentheses.

\begin{tabular}{|c|c|c|c|c|c|c|c|}
\hline \multirow{3}{*}{ Composition of thin film } & \multicolumn{2}{|c|}{ Spectrophotometric } & \multicolumn{5}{|c|}{ Ellipsometric } \\
\hline & \multirow[b]{2}{*}{$d_{\text {unexp }}[\mathrm{nm}]$} & \multirow[b]{2}{*}{$n_{\text {unexp }}$} & \multicolumn{2}{|c|}{ Multiple-angle calculation } & \multicolumn{3}{|c|}{ Single-angle calculation } \\
\hline & & & $d_{\text {unexp }}[\mathrm{nm}]$ & $n_{\text {unexp }}$ & $n_{\text {unexp }}\left(45^{\circ}\right)$ & $n_{\text {unexp }}\left(50^{\circ}\right)$ & $n_{\text {unexp }}\left(55^{\circ}\right)$ \\
\hline $\begin{array}{l}\mathrm{As}_{28} \mathrm{~S}_{72} \\
\left(\mathrm{As}_{28.5} \mathrm{~S}_{71.5}\right)\end{array}$ & 977 & 2.35 & 978 & 2.347 & 2.353 & 2.352 & 2.351 \\
\hline $\begin{array}{l}\mathrm{As}_{40} \mathrm{~S}_{60} \\
\left(\mathrm{As}_{40.7} \mathrm{~S}_{59.3}\right)\end{array}$ & 943 & 2.46 & 937 & 2.457 & 2.452 & 2.457 & 2.454 \\
\hline $\begin{array}{l}\mathrm{As}_{45} \mathrm{~S}_{55} \\
\left(\mathrm{As}_{43.3} \mathrm{~S}_{56.7}\right)\end{array}$ & 898 & 2.45 & 897 & 2.449 & 2.451 & 2.448 & 2454 \\
\hline $\begin{array}{l}\mathrm{GeS}_{2} \\
\left(\mathrm{Ge}_{35.1} \mathrm{~S}_{64.9}\right)\end{array}$ & 987 & 2.16 & 970 & 2.172 & 2.167 & 2.163 & 2.168 \\
\hline $\begin{array}{l}\mathrm{As}_{10} \mathrm{Ge}_{30} \mathrm{~S}_{60} \\
\left(\mathrm{As}_{10.7} \mathrm{Ge}_{32.9} \mathrm{~S}_{56.4}\right)\end{array}$ & 1217 & 2.34 & 1208 & 2.360 & 2.362 & 2.353 & 2.346 \\
\hline $\begin{array}{l}\mathrm{As}_{40} \mathrm{~S}_{30} \mathrm{Se}_{30} \\
\left(\mathrm{As}_{39} \mathrm{~S}_{32} \mathrm{Se}_{29}\right)\end{array}$ & 996 & 2.72 & 997 & 2.722 & 2.719 & 2.719 & 2.722 \\
\hline $\begin{array}{l}\mathrm{Ge}_{32} \mathrm{~S}_{64} \mathrm{Ga}_{4} \\
\left(\mathrm{Ge}_{39.6} \mathrm{~S}_{58.6} \mathrm{Ga}_{1.6}\right)\end{array}$ & 905 & 2.25 & 871 & 2.236 & 2.215 & 2.321 & 2.346 \\
\hline $\begin{array}{l}\mathrm{Ge}_{32} \mathrm{~S}_{64} \mathrm{In}_{4} \\
\left(\mathrm{Ge}_{38.5} \mathrm{~S}_{60.1} \operatorname{In}_{1.4}\right)\end{array}$ & 1270 & 2.27 & 970 & 2.220 & 2,086 & 2,215 & 2,299 \\
\hline $\begin{array}{l}\mathrm{Ge}_{32} \mathrm{~S}_{64} \mathrm{Tl}_{4} \\
\left(\mathrm{Ge}_{33.3} \mathrm{~S}_{65.0} \mathrm{Tl}_{1.7}\right)\end{array}$ & 1388 & 2.26 & 1408 & 2.204 & 2.235 & 2.389 & 2.447 \\
\hline $\begin{array}{l}\mathrm{Ge}_{28} \mathrm{~S}_{66} \mathrm{Bi}_{6} \\
\left(\mathrm{Ge}_{31.4} \mathrm{~S}_{65.9} \mathrm{Bi}_{2.7}\right)\end{array}$ & 1390 & 2.19 & 1291 & 2.256 & 2.161 & 2.264 & 2.255 \\
\hline $\begin{array}{l}\mathrm{As}_{39} \mathrm{~S}_{58} \mathrm{Bi}_{3} \\
\left(\mathrm{As}_{46.9} \mathrm{~S}_{52.0} \mathrm{Bi}_{1.1}\right)\end{array}$ & 1014 & 2.29 & 1122 & 2.367 & 2.493 & 2.477 & 2.467 \\
\hline $\begin{array}{l}\mathrm{As}_{38} \mathrm{~S}_{56} \mathrm{Bi}_{6} \\
\left(\mathrm{As}_{45.0} \mathrm{~S}_{51.7} \mathrm{Bi}_{2.3}\right)\end{array}$ & 1201 & 2.49 & 996 & 2.789 & 2.805 & 2.751 & 2.694 \\
\hline $\begin{array}{l}\mathrm{As}_{38} \mathrm{~S}_{56} \mathrm{Tl}_{6} \\
\left(\mathrm{As}_{43.6} \mathrm{~S}_{54.0} \mathrm{Tl}_{2.4}\right)\end{array}$ & 1117 & 2.64 & 930 & 2.712 & 2.690 & 2.718 & 2.721 \\
\hline $\begin{array}{l}\mathrm{As}_{2} \mathrm{~S}_{3} / \mathrm{Bi} \\
\left(\mathrm{As}_{41.3} \mathrm{~S}_{53.5} \mathrm{Bi}_{5.2}\right)\end{array}$ & 1065 & 2.64 & 1067 & 2.632 & 2.639 & 2.632 & 2.627 \\
\hline $\begin{array}{l}\mathrm{As}_{2} \mathrm{~S}_{3} / \mathrm{Tl} \\
\left(\mathrm{As}_{43.5} \mathrm{~S}_{54.5} \mathrm{Tl}_{2.0}\right)\end{array}$ & 1341 & 2.499 & 1342 & 2.492 & 2.493 & 2.495 & 2.496 \\
\hline $\begin{array}{l}\mathrm{As}_{2} \mathrm{~S}_{3} / \mathrm{In}_{2} \mathrm{~S}_{3} \\
\left(\mathrm{As}_{31.1} \mathrm{~S}_{60.7} \mathrm{In}_{8.2}\right)\end{array}$ & 805 & 2.53 & 800 & 2.528 & 2.524 & 2.528 & 2.527 \\
\hline
\end{tabular}

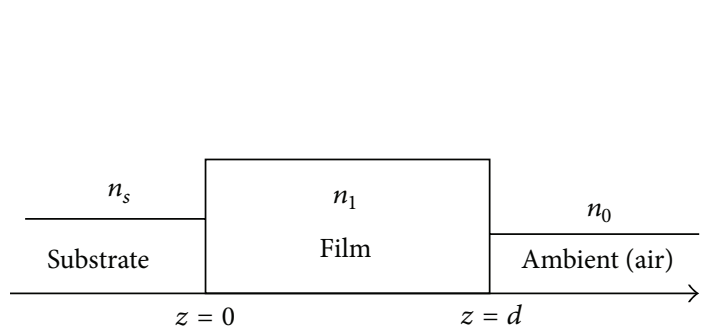

(a)

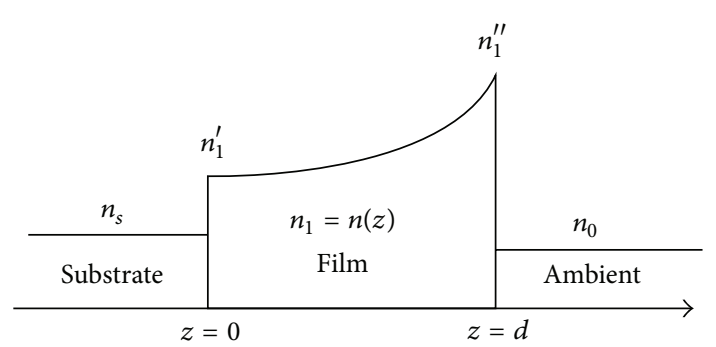

(b)

FIGURE 1: Schematic presentation of homogenous thin film with refractive index, $n_{1}$, and thickness, $d$, (a) and inhomogeneous thin film (b). 
is available for the profile, best-fit result out of the experimental set of values of $\Psi$ and $\Delta$ should be used.

The dependence of $\Psi$ and $\Delta$ on the system parameters in (3) for a three-phase system can be expressed by the following analytical function:

$$
\begin{gathered}
\Psi=\tan ^{-1}\left[\rho\left(n_{0}, n_{1}, k_{1}, n_{s}, k_{s}, d, \phi, \lambda\right)\right], \\
\Delta=\arg \left[\rho\left(n_{0}, n_{1}, k_{1}, n_{s}, k_{s}, d, \phi, \lambda\right)\right],
\end{gathered}
$$

where $n_{0}$ is the refractive index of ambient (in case of air, $n_{0}=1$ ), and $n_{s}$ and $k_{s}$ are the refractive index and extinction coefficient of the substrate, respectively. An essential problem of all forms of ellipsometry is the impossibility of inverting (6) in order to obtain the complex refractive index parameters. The methods applied for solving the system of (6) using multiangle measurements were described in [1]. In many cases these parameters are varied in order to minimize some function. One of the most often used estimators is

$$
G=\sum_{i=1}^{M}\left(\frac{\left(\Delta_{i}^{c}-\Delta_{i}^{m}\right)^{2}}{\delta \Delta^{2}}+\frac{\left(\Psi_{i}^{c}-\Psi_{i}^{m}\right)^{2}}{\delta \Psi^{2}}\right),
$$

where $M$ is the number of the experimental points (angles of incidence in our case), $\Delta_{i}^{c}$ and $\Psi_{i}^{c}$ are the theoretical values of the ellipsometric angles at a determined group of optical parameters for the applied model, and $\Delta_{i}^{m}$ and $\Psi_{i}^{m}$ are the measured values. The fitting process includes a choice of suitable initial values for the unknown parameters and the minimization of the function $G$ using the fitting procedure based on the Levenberg-Marquardt algorithm. The initial estimates of the parameters were simultaneously varied until a fit was obtained between the experimental data and the values calculated from the thin film formula (3). The good coincidence between the measured and theoretical values of the ellipsometric angles within the defined accuracy is an evidence of felicitous choice of a model of the investigated system [5, 43]. The error is calculated from the elements of the correlation matrix which the Levenberg-Marquardt algorithm produces during the minimization procedure. The calculation procedure is described in $[1,5]$.

\section{Results and Discussion}

Knowledge of the optical parameters of the single layers is important for successful engineering of multilayer structures. Firstly, we determined the optical parameters of the thin films using the single homogenous absorbing layer model and applying multiangle measurements $\left(45,50\right.$, and $\left.55^{\circ}\right)$. In this case the refractive index, $n$, extinction coefficient, $k$, and thickness, $d$, are simultaneously calculated (three-parameter calculation). We found that the maximal experimental error of $n$ was $\Delta n= \pm 0.005-0.007$ [26]. The basic advantage of the multiangle measurements consists in their independence on the half-wave point of light incidence angle [44]. Further, we used the calculated optical parameters from multiangle measurement as an initial estimate of the unknown parameters for single-angle calculations in order to determine the degree of inhomogeneity of the thin layers. We searched for two optical parameters of the thin film and the third one has been iterated with small steps around its approximate value until minimum value of $G$ was found [26]. The singleangle calculation allows the film's thickness to be calculated with an accuracy better than $0.3 \%$. We showed that in case of homogenous thin films, both single- and multiple-angle methods gave the same results.

In Table 1 a comparison of the thickness and refractive index values of thin films calculated from ellipsometric measurements and/or from their transmission spectra using Swanepoel's method [45] is presented. The measurements were performed on one spot of each sample. The areas of the incident probe beams of the spectrophotometer and the ellipsometer were 50 and $1 \mathrm{~mm}^{2}$, respectively.

For thin As-S films the values for the refractive index within the limits of the experimental error obtained through ellipsometry are in a good agreement with those calculated from spectrophotometric measurements. The single-angle calculations at different angles show that thin films from As-S(Se), Ge-S, As-Ge-S systems are homogenous or their inhomogeneity cannot be revealed since the discrepancies are within the experimental error. It is seen that the optical constants and thickness for layers from Ge-S-Ga(In, Tl, Bi) and $\mathrm{As}-\mathrm{S}-\mathrm{Bi}(\mathrm{Tl})$ systems as derived by ellipsometry differ from those calculated from spectrophotometric measurements. At the same time the difference in the values of $n$ independently determined at $45^{\circ}, 50^{\circ}$, and $55^{\circ}$ is higher than the experimental error $\Delta n= \pm 0.005$. It is seen from (4) and (5) that in case of inhomogeneous coatings, due to different paths of the laser beam of the ellipsometer, different values for $n$ would be observed. These considerations suggest inhomogeneity of the thin films deposited form bulk glasses from $\mathrm{As}-\mathrm{S}-\mathrm{Bi}(\mathrm{Tl})$ systems. The derived values of $n$, thus, can be regarded just as effective values. We used the method of thermal coevaporation to deposit thin films from ternary $\mathrm{As}_{2} \mathrm{~S}_{3}-\mathrm{In}_{2} \mathrm{~S}_{3}$ system [46] and thin films from multicomponent $\mathrm{GeSe}_{2}-\mathrm{Sb}_{2} \mathrm{Se}_{3}$-AgI system [47]. In Table 1 the refractive index of thin $\mathrm{As}_{2} \mathrm{~S}_{3} / \mathrm{Bi}, \mathrm{As}_{2} \mathrm{~S}_{3} / \mathrm{Tl}$, and $\mathrm{As}_{2} \mathrm{~S}_{3} / \mathrm{In}_{2} \mathrm{~S}_{3}$ films deposited by coevaporation is given. It is seen from single-angle calculations that the co-evaporation from two sources makes possible the deposition of homogenous coatings from the above multicomponent glasses.

Our results for the optical constants and thickness of thin films from As-S-Ge, $\mathrm{As}_{x} \mathrm{Se}_{100-x}$, and $\mathrm{Ge}_{x} \mathrm{~S}_{100-x}$ systems and their changes after illumination by halogen lamp are presented in Table 2. It is seen that the refractive index of the chalcogenide films varies in wide diapason, that is, from 2.05 to 3.15 for $\mathrm{GeS}_{2}$ and $\mathrm{As}_{2} \mathrm{Se}_{3}$, respectively. The results for $n$ and $k$ of the films from $\mathrm{As}-\mathrm{S}=(\mathrm{Se})$ systems are in agreement with the data reported in the literature [29, 48-50], With the substitution of Se for S in thin As-S-Se layers, the refractive index of the layers increases and the highest value is reached for $\mathrm{As}_{2} \mathrm{Se}_{3}$ film. The changes in the optical parameters of thin As-Se films under illumination are more pronounced compared to those in As-S layers. Maximum changes in the refractive index of the As-Se films were observed for the thin film with composition $\mathrm{As}_{50} \mathrm{Se}_{50}(\Delta n=+0.23)$. The refractive index of the thin films from Ge-S system decreases after 
TABLE 2: Optical constants (refractive index, $n$, extinction coefficient, $k$ ) at $\lambda=632.8 \mathrm{~nm}$ and thickness, $d$ of thin chalcogenide films before and after light exposure.

\begin{tabular}{|c|c|c|c|c|c|c|}
\hline Composition of thin film & $n_{\text {unexp }}$ & $n_{\exp }$ & $k_{\text {unexp }}$ & $k_{\exp }$ & $d_{\text {unexp }}[\mathrm{nm}]$ & $d_{\exp }[\mathrm{nm}]$ \\
\hline $\mathrm{As}_{40} \mathrm{~S}_{60}$ & 2.458 & 2.531 & 0.001 & 0.003 & 1032 & 996 \\
\hline $\mathrm{As}_{10} \mathrm{Ge}_{30} \mathrm{~S}_{60}$ & 2.320 & 2.226 & 0 & 0.001 & 1208 & 1279 \\
\hline $\mathrm{As}_{20} \mathrm{Ge}_{20} \mathrm{~S}_{60}$ & 2.393 & 2.300 & 0 & 0 & 1172 & 1202 \\
\hline $\mathrm{As}_{30} \mathrm{Ge}_{10} \mathrm{~S}_{60}$ & 2.438 & 2.415 & 0.003 & 0.003 & 1128 & 1136 \\
\hline $\mathrm{Ge}_{20} \mathrm{~S}_{80}$ & 2.138 & 2.079 & 0 & 0 & 741 & 775 \\
\hline $\mathrm{Ge}_{33} \mathrm{~S}_{67}$ & 2.172 & 2.056 & 0.005 & 0 & 970 & 990 \\
\hline $\mathrm{Ge}_{40} \mathrm{~S}_{60}$ & 2.577 & 2.524 & 0.001 & 0 & 1187 & 1218 \\
\hline $\mathrm{As}_{28} \mathrm{Se}_{72}$ & 2.979 & 3.047 & 0.039 & 0.037 & 893 & 929 \\
\hline $\mathrm{As}_{40} \mathrm{Se}_{60}$ & 3.031 & 3.155 & 0.036 & 0.054 & 822 & 801 \\
\hline $\mathrm{As}_{50} \mathrm{Se}_{50}$ & 2.874 & 3.101 & 0.014 & 0.041 & 803 & 795 \\
\hline $\mathrm{As}_{40} \mathrm{~S}_{45} \mathrm{Se}_{15}$ & 2.567 & 2.687 & $<0.001$ & $<0.001$ & 1045 & 1035 \\
\hline $\mathrm{As}_{40} \mathrm{~S}_{30} \mathrm{Se}_{30}$ & 2.763 & 2.820 & 0.007 & 0.013 & 997 & 985 \\
\hline $\mathrm{As}_{40} \mathrm{~S}_{15} \mathrm{Se}_{45}$ & 2.845 & 2.991 & 0.013 & 0.043 & 879 & 865 \\
\hline
\end{tabular}

TABLE 3: Refractive index, $n$, and thickness, $d$, of thin films, determined by ellipsometric, triple and double spectrophotometric methods. $T$ is the transmission, $R_{f}, R_{b}$, and $R_{m}$ are the reflections from the front and back side of the BK-7 substrate and from the film deposited on Si-wafer substrate, respectively.

\begin{tabular}{lcccccrrr}
\hline \multirow{2}{*}{ Composition } & \multicolumn{2}{c}{$\left(T, R, R_{m}\right)$ method } & \multicolumn{2}{c}{ Ellipsometric } & \multicolumn{2}{c}{$\left(T, R_{f}\right)$ method } & \multicolumn{2}{c}{ Ellipsometric } \\
& $d_{\text {unexp }}[\mathrm{nm}]$ & $d_{\text {exp }}[\mathrm{nm}]$ & $d_{\text {unexp }}[\mathrm{nm}]$ & $d_{\exp }[\mathrm{nm}]$ & $n_{\text {unexp }}$ & $n_{\exp }$ & $n_{\text {unexp }}$ & $n_{\exp }$ \\
\hline $\mathrm{As}_{40} \mathrm{~S}_{60}$ & 74 & 72 & 74.0 & 72.5 & 2.46 & 2.58 & 2.457 \\
$\mathrm{GeS}_{2}$ & 48 & 50 & 47.0 & 49.7 & 2.15 & 2.11 & 2.131 \\
$\mathrm{As}_{20} \mathrm{Ge}_{20} \mathrm{~S}_{60}$ & 80 & 85 & 81.8 & 86.2 & 2.35 & 2.30 & 2.369 & 2.096 \\
$\mathrm{As}_{10} \mathrm{Ge}_{30} \mathrm{~S}_{60}$ & 95 & 91 & 93.6 & 91.5 & 2.32 & 2.23 & 2.336 \\
$\mathrm{As}_{40} \mathrm{~S}_{30} \mathrm{Se}_{30}$ & 73 & 72 & 74.2 & 73.7 & 2.74 & 2.94 & 2.722 \\
$\mathrm{As}_{40} \mathrm{Se}_{60}$ & 70 & 65 & 69.3 & 65.6 & 3.05 & 3.31 & 3.056 & 3.94 \\
\hline
\end{tabular}

exposure. The greatest changes were observed for thin film with stoichiometric composition $\mathrm{GeS}_{2}$.

The photo-induced volume effects in thin chalcogenide films are connected with changes of their thickness. From practical point of view, volume changes make chalcogenide layers perspective materials for fabrication of microlenses [21]. An effect of photocontraction was found after exposure to light of thin films from As-S(Se) (see Table 2). In Figure 2 the relative changes of the thickness, $\Delta d / d_{\text {unexp }}$ as a function of the composition for As-S, Ge-S, $\mathrm{As}_{40} \mathrm{~S}_{60-x} \mathrm{Se}_{x}$, and As$\mathrm{S}-\mathrm{Ge}$ films are presented. It is seen that the layer from As-S and $\mathrm{As}_{40} \mathrm{~S}_{60-x} \mathrm{Se}_{x}$ systems exhibited effect of photocontraction. The changes in the thickness increase with sulphur contain in layers from binary As-S system. A pure effect of photoexpansion is observed for thin Ge-S layers after illumination, while for As-S-Ge system, both effects of photocontraction and photoexpansion are presented. We have obtained the maximal value of photoexpansion for thin film with composition $\mathrm{As}_{10} \mathrm{Ge}_{30} \mathrm{~S}_{60}(\Delta d / d=+7.6 \%)$. We have obtained the maximal value of photoexpansion for thin film with composition $\mathrm{As}_{10} \mathrm{Ge}_{30} \mathrm{~S}_{60}(\Delta d / d=+7.6 \%)$. This result is in agreement with data published by other authors [51].

To understand the origin of inhomogeneity of the thin films, we investigated the thickness dependence of the refractive index. For the most photonic devices, it is necessary that the thin layers are with an exact thickness. The accumulated knowledge of the refractive index and its photo-induced changes would support the modelling and manufacturing of 1D photonic crystal [52]. The results from our investigations on the thickness dependence of the optical properties of thin films from As-Se, Ge-S, As-Ge-S, and As-S-Se systems [25-27] showed that the refractive index is independent of $d$ for $d>50 \mathrm{~nm}$. For acquiring of information about the possible changes of the optical constants during the process of measurement with $\mathrm{He}-\mathrm{Ne}$ laser, we compared the values of $n, k$, and $d$ for thin films obtained by MAI-ellipsometry with those determined by two and three spectrophotometric measurements [53] (Table 3).

In Figure 3(a) a theoretical, as well as, experimental $\Psi$ $\Delta$ dependence at room temperature is given for thin $\mathrm{As}_{2} \mathrm{~S}_{3}$ films $(d=25-100 \mathrm{~nm})$ with refractive index $n=2.45$ at $\lambda$ $=632.8 \mathrm{~nm}$ and angle of light incidence $\varphi=50^{\circ}$. It is seen that the experimental results follow the theoretical curve for $d>50 \mathrm{~nm}$. The thickness dependence of the ellipsometric angles $\Psi-\Delta$ of thin films with compositions $\mathrm{As}_{40} \mathrm{~S}_{30} \mathrm{Se}_{30}$ and $\mathrm{As}_{40} \mathrm{Se}_{60}$ is presented in Figures 3(b) and 3(c), respectively. The parameters of theoretical curves are $n=2.72$ and $k=$ 0.001 or $n=3.05$ and $k=0.03$ at $\lambda=632.8 \mathrm{~nm}$ and angle of light incidence $\varphi=50^{\circ}$ for thin films with composition $\mathrm{As}_{40} \mathrm{~S}_{30} \mathrm{Se}_{30}$ and $\mathrm{As}_{40} \mathrm{Se}_{60}$, respectively. 


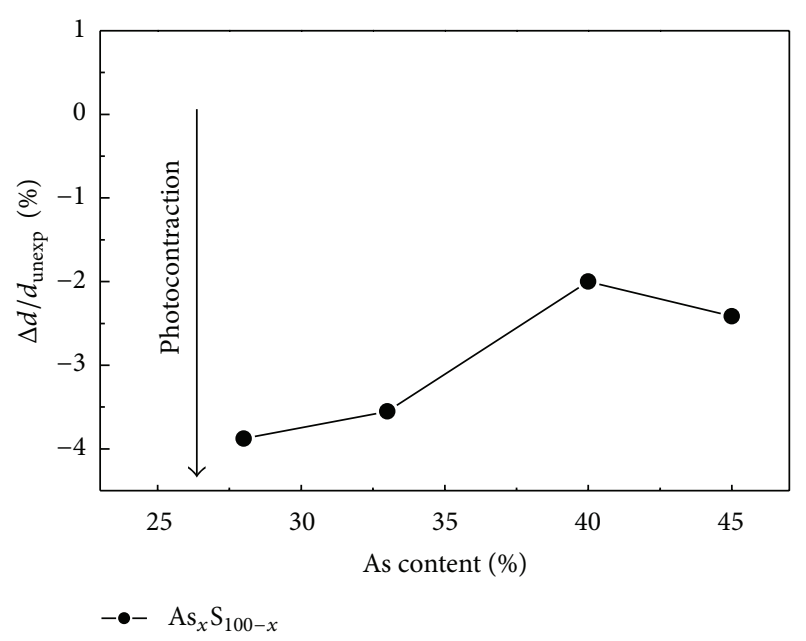

(a)

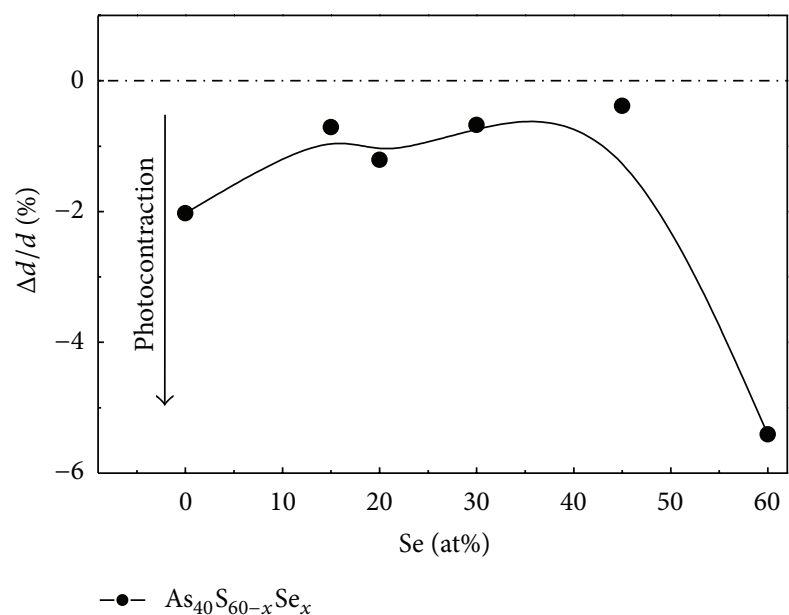

(c)

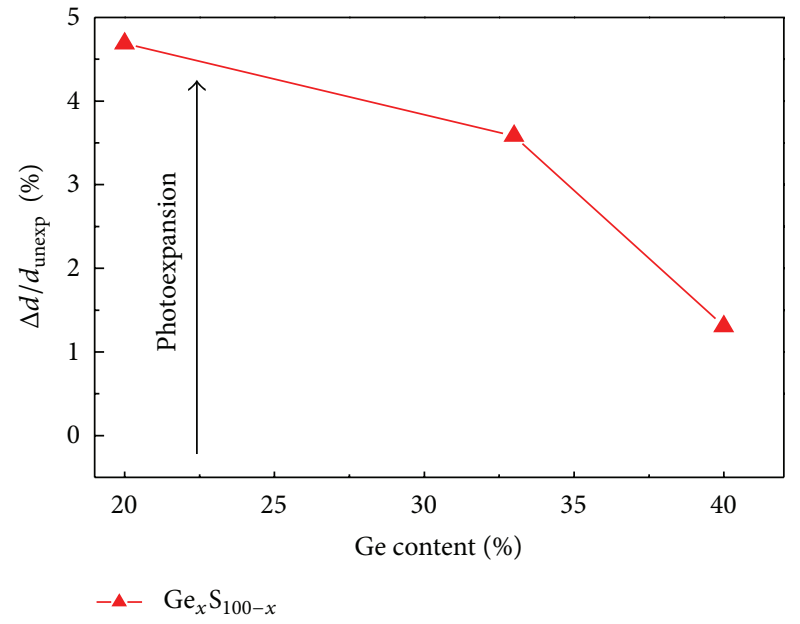

(b)

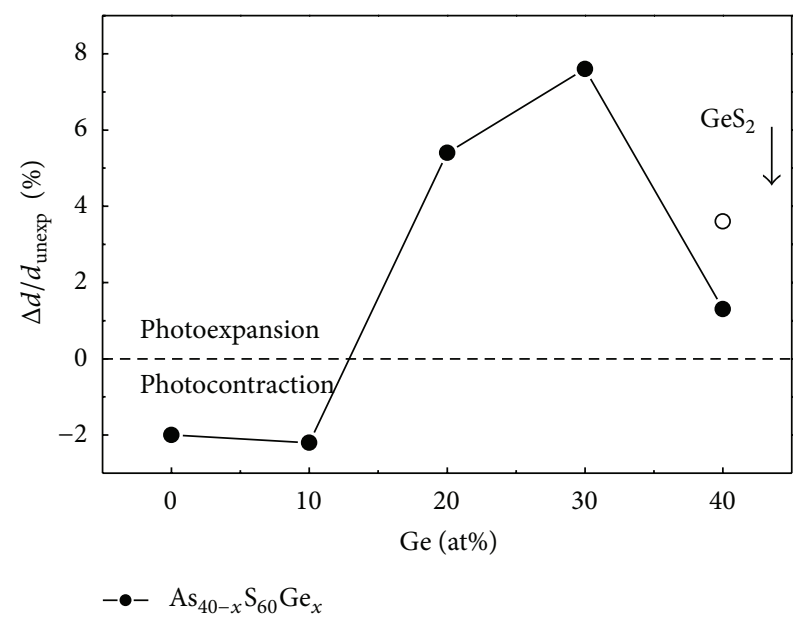

(d)

FIGURE 2: Relative changes in the thickness, $\Delta d / d_{\text {unexp }}$, of thin films from the As-S (a), Ge-S (b), As-S-Se (c), and As-S-Ge (d) systems after exposure to white light as a function of Se and Ge content, respectively, (the lines connecting the experimental points are only drawn as a guide to the eye).

It is observed that $n$ is independent of the thickness for $d>50 \mathrm{~nm}$. We believe that the optical properties of the films thinner than $50 \mathrm{~nm}$ are strongly influenced by the substrate and the process of the thin films growth. The single homogenous absorbing layer model is only an approximation, since it does not consider either the existence of the substrate/film interface, the surface roughness, or oxidation. We can expect that the error of determination of $d$ increases extremely for $d<30 \mathrm{~nm}[54,55]$. The relative error in the thickness determination is independent of $d$ for layers with $d>70 \mathrm{~nm}( \pm 0.3 \%)$, and downwards it increases up to $1 \%$ for layers with $\mathrm{d} \sim 30 \mathrm{~nm}$. The error of the refractive index determination is weakly affected $( \pm 0.2-0.3 \%)$ by the layer's thickness [24].

It is seen from Table 1 that the composition of thin films from As-S-Bi is different from that of the respective bulk sample. We made the composition analysis of the residue in the boat that was found to be $\mathrm{As}_{0.5} \mathrm{~S}_{59.3} \mathrm{Bi}_{40.2}$ after evaporation of thin film from bulk $\mathrm{As}_{38} \mathrm{~S}_{56} \mathrm{Bi}_{6}$ glass. That is why firstly we analyzed the thin As-S-Bi films using the two-layer model considering an absorbing sublayer on the upper part of the coating (closer to air) when the whole quantity in the boat was evaporated. This model gives the best fit of the experimental results (Figure 4). The results show a higher extinction coefficient, $k$, of the upper sublayer. The thicknesses of the layers for thin films with compositions $\mathrm{As}_{39} \mathrm{~S}_{58} \mathrm{Bi}_{3}$ and $\mathrm{As}_{34} \mathrm{~S}_{54} \mathrm{Bi}_{10}$ system were 39 and $70 \mathrm{~nm}$, respectively. The $\mathrm{X}$-ray microanalyses at different acceleration voltage [39] showed that concentration of $\mathrm{Bi}$ or $\mathrm{Tl}$ increases in direction from the substrate to the interface of the layer with the ambient. In [56] it was found by mass-spectroscopy analysis that the vapour of $\mathrm{As}_{2} \mathrm{~S}_{3}$, formed in the process of thermal evaporation, consists of different sulphur- or arsenic-rich fractions. These fractions polymerize on the substrate forming the glass network of the thin film. This finding suggests that the melt in the boat should become poorer of light fractions during the thermal 


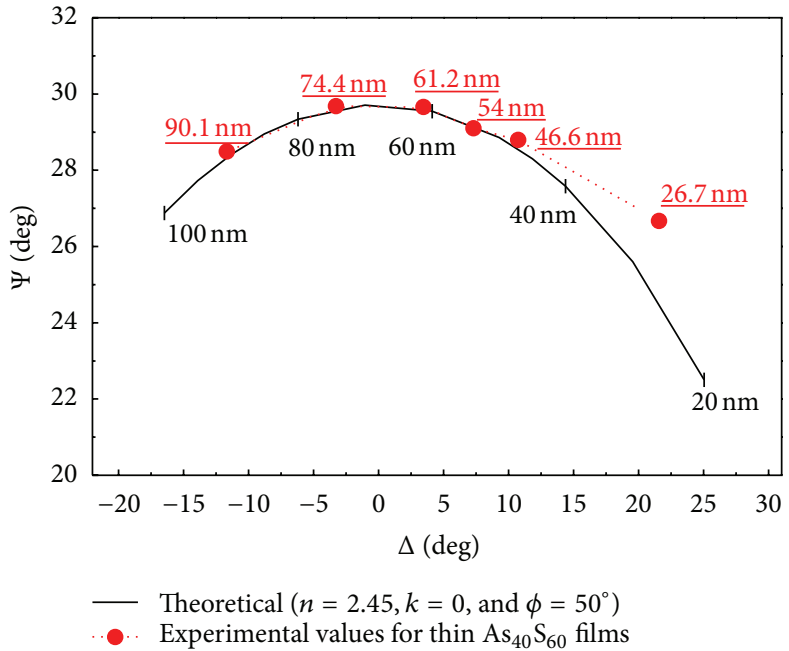

(a)

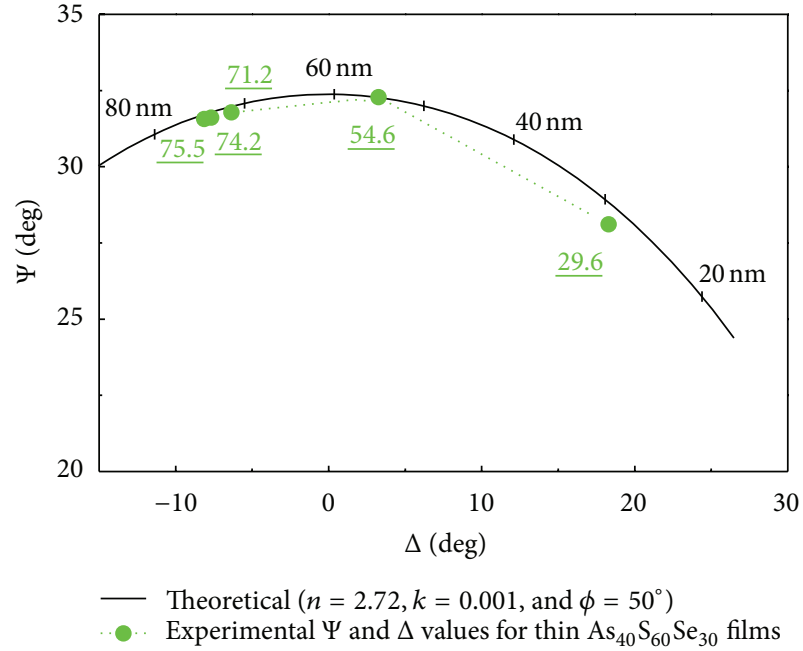

(b)

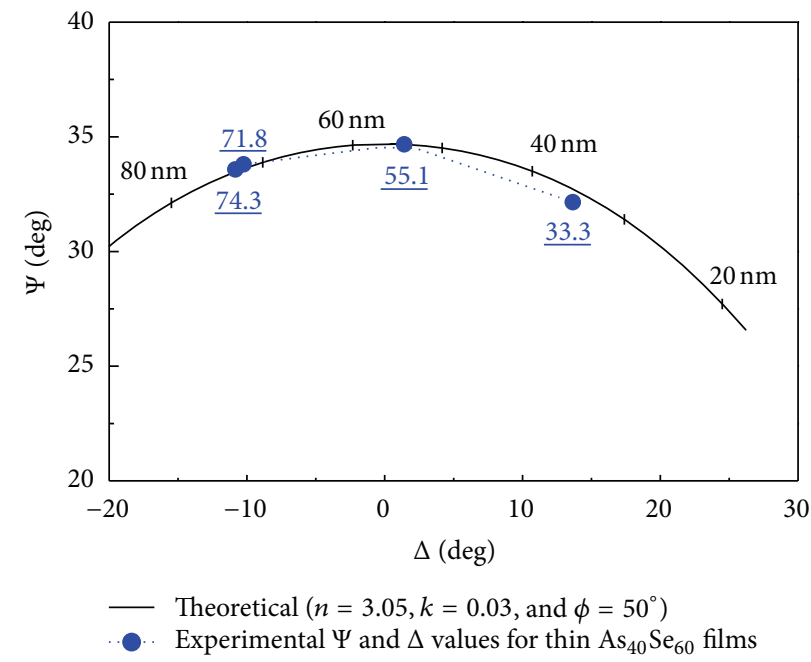

(c)

Figure 3: Theoretical $\Psi-\Delta$ dependence for thin $\mathrm{As}_{40} \mathrm{~S}_{60-x} \mathrm{Se}_{x}$ films and the experimental data for thin (a) $\mathrm{As}_{40} \mathrm{~S}_{60}$, (b) $\mathrm{As}_{40} \mathrm{~S}_{30} \mathrm{Se}_{30}$, and (c) $\mathrm{As}_{40} \mathrm{Se}_{60}$ films. The parameters of the theoretical curves are given in the graphs. The calculated film's thickness is underlined (the dotted lines connecting the experimental points are only drawn as a guide to the eye).

evaporation, and therefore the upper part of the thin films should be enriched with structural units formed from heavier fractions. Most probably this is the reason why in some cases inhomogeneous layers are produced by thermal evaporation. This phenomenon is more pronounced for thin films from the ternary As-S-Tl(Bi) systems $[39,57]$.

Usually inhomogeneous thin films are presented as multilayer coatings where the refractive index is assumed to be variable under some mathematical function-linear, exponential and Gaussian [58]. In many cases, it is not possible to determine the manner in which the refractive index of the film varies. For estimation of the optical homogeneity in the volume of the thin layers, thin films (about $80-100 \mathrm{~nm}$ thick) were deposited consecutively on different substrates until the whole quantity in the boat was evaporated. We expect that the dependence of the refractive index of the discrete layers on the order of their deposition would be the same as the profile of $n$ in the one micron integral coating. Figure 5 represents the distribution of the refractive index, $n$, on the total thickness of the sublayers for unexposed $\mathrm{As}_{40} \mathrm{~S}_{60}$ and $\mathrm{As}_{38} \mathrm{~S}_{56} \mathrm{Tl}_{6}$ layers. It is seen that the refractive index for as-deposited $\mathrm{As}_{40} \mathrm{~S}_{60}$ films does not change with the stack order, while $n$ considerably increases for the last two numbers of the system $\mathrm{As}_{38} \mathrm{~S}_{56} \mathrm{Tl}_{6}$. It can be concluded therefore that the $\mathrm{As}_{2} \mathrm{~S}_{3}$ thin films are homogeneous in composition in depth of the films, while during the process of vacuum deposition of As-S-Tl coatings, a process of decomposition takes place. This fact suggests that we can consider $\mathrm{As}_{38} \mathrm{~S}_{56} \mathrm{Tl}_{6}$ film to be composed of two parts: homogenous sublayer with low refractive index and inhomogeneous sublayer on the upper surface of the coating. The X-ray microanalysis of the composition of the sublayers revealed variation between 


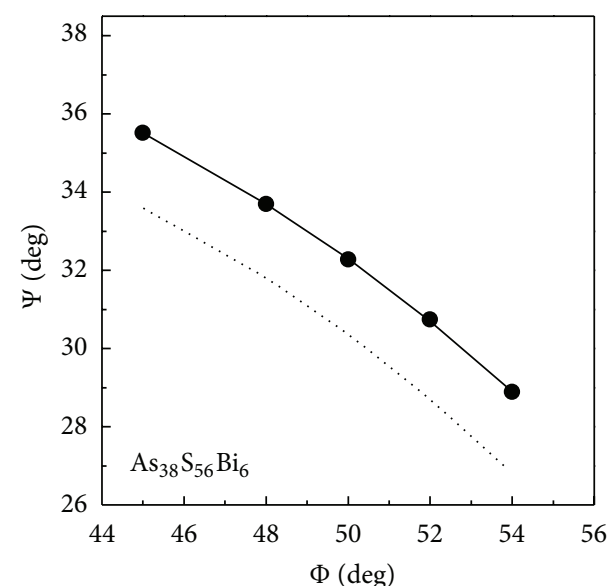

Theoretical:

..... Single-layer model

_ Double-layer model

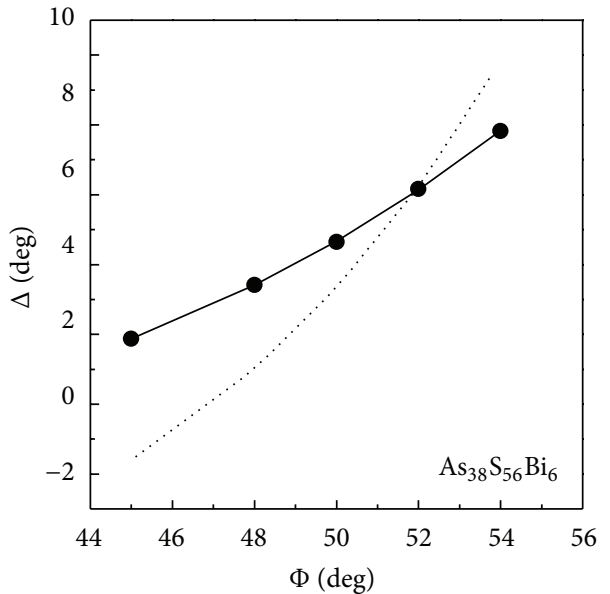

Theoretical:

..... Single-layer model

_ Double-layer mode

(a)

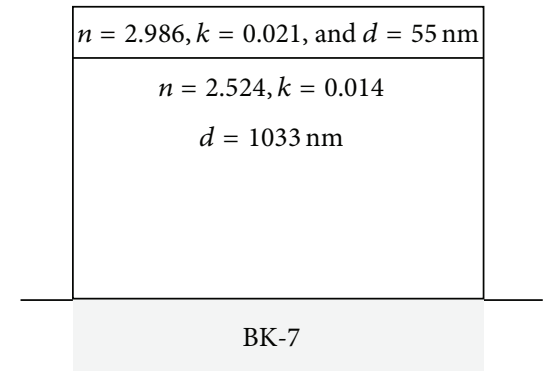

(b)

Figure 4: Comparison of theoretical (dotted and solid lines for single and double layer models, resp.) and experimental values (symbols) of $\Psi$ and $\Delta$ for thin $\mathrm{As}_{38} \mathrm{~S}_{56} \mathrm{Bi}_{6}$ film depending on the angle of light incidence (a) and schematic representation of the two-layer model with calculated values for optical parameters (b).

$0.1-0.6$ at $\%$ of the thallium content in the samples from 1 to 6, while the compositions for the sublayers 7 and 8 were $\mathrm{As}_{32.6} \mathrm{~S}_{62.3} \mathrm{Tl}_{8.1}$ and $\mathrm{As}_{5.6} \mathrm{~S}_{59.5} \mathrm{Tl}_{34.9}$, respectively. It is known that in case linear profile of the average values for refractive index, $n_{\mathrm{av}}$, is equal to the refractive index at the thickness level $0.5 d$ [59]. The dependence presented in Figure 5 can be extrapolated by exponential function of the type $n=n_{0}+$ $A \cdot \exp (x / B)$, where $n_{0}$ is the value of the refractive index of the film close to substrate. Having determined the optical parameters and thickness of the single layers, we calculated the theoretical ellipsometric angles $\Psi$ and $\Delta$ of the complex structure [60]. Further to finding the effective value of $n$ we used these values to calculate refractive index of such coating as the integral film. We found that the effective value of $n$ was 2.679 that is close to the one determined for one-micron layer evaporated from bulk glass (see Table 1).

The thin films deposited from bulk $\mathrm{As}_{38} \mathrm{~S}_{56} \mathrm{Bi}_{6}$ glass showed similar dependence of $n$ on their deposition number (Figure 6). This dependence suggests that metal content increases extremely in the last two samples. The calculated values for $n$ for $i=8$ is lower than those calculated from

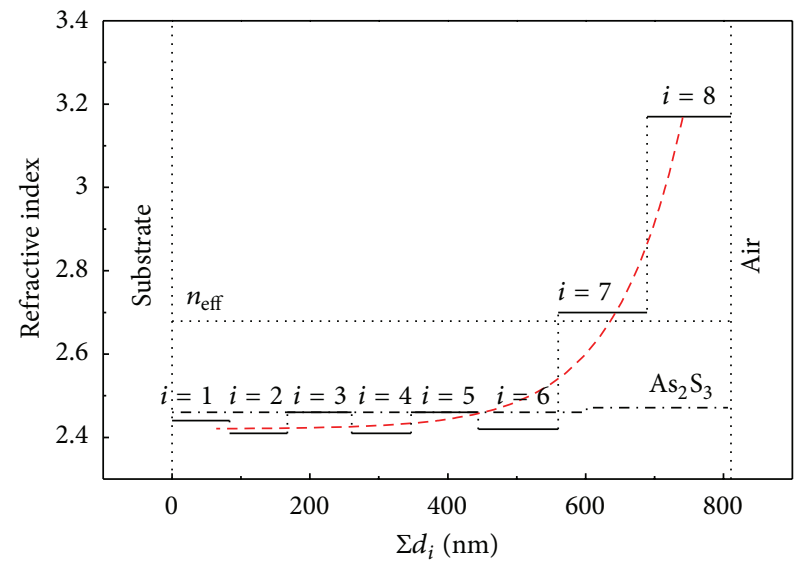

FIGURE 5: Variation of the refractive index depending on the order of deposition of discrete films $(i=1-8)$ from bulk $\mathrm{As}_{38} \mathrm{~S}_{56} \mathrm{Tl}_{6}$ glass. The effective value of the refractive index of the coating is given as $n_{\text {eff }}$ (dotted line). The exponential extrapolation of the variation of $n$ of sublayers is given by dashed line. The dashed-dotted line represents the same dependence for thin $\mathrm{As}_{40} \mathrm{~S}_{60}$ layers. 


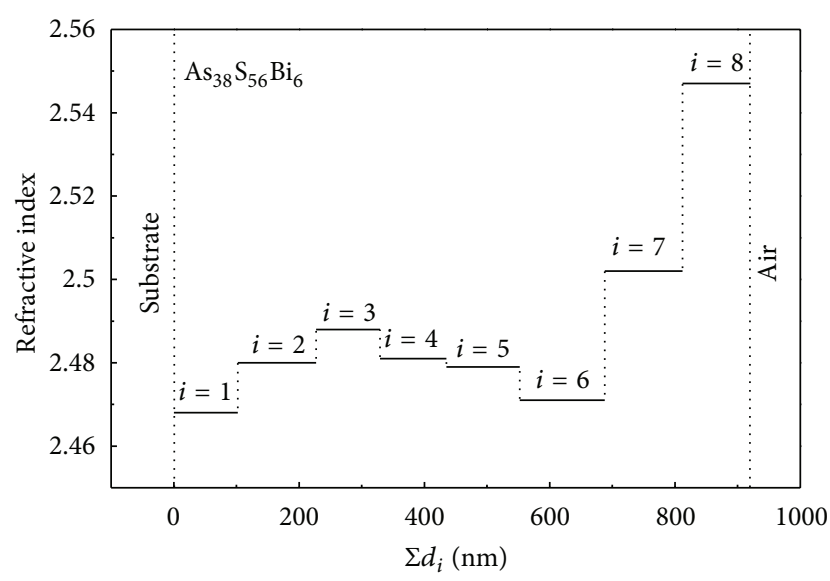

Figure 6: Variation of the refractive index depending on the order of deposition of discrete films $(i=1-8)$ from bulk $\mathrm{As}_{38} \mathrm{~S}_{56} \mathrm{Bi}_{6}$ glass.

two-layer model (see Figure 4(b)) since in the former case it is averaged over higher thickness $(d=107 \mathrm{~nm})$.

In the existing methods the profile is determined using virtual slicing of the thin film into sublayers, suggestion of some function of the dependence of the refractive index in the depth of the coating (linear, exponential, or polynomial) and minimization of the discrepancy between theoretically calculated and measured values of $\Psi$ and $\Delta$ [61]. In contrast, the previously suggested method requires no mathematical function and provides reliable information for the refractive index profile in the depth of thin films. The gradient of $n$ due to variation of composition in the depth of the layer could replace the design of column structures in the construction of multilayer structure $[62,63]$.

\section{Conclusion}

The surface roughness plays a key role in the formation of the interface between layers in multilayer structures. The effects of surface oxidation observed in thin films [40] could be determining in the formation of this interface and their presence indirectly demonstrated. In [24] it was shown that the introducing of a surface layer with $n=1.46$ considerably improves the accuracy of the fit of the experimental data for $\Psi$ and $\Delta$ for $\mathrm{As}_{2} \mathrm{~S}_{3}$ film. The thickness of the surface overlayer is in the range of 2-15 $\mathrm{nm}[26,28]$. Our investigation on surface roughness by White Light Interferometric Profiler [64] shows that the root mean square (rms) is about $1.0-8.6 \mathrm{~nm}$ for As$\mathrm{S}-\mathrm{Se} / \mathrm{Ag}$ layer with thickness about $700 \mathrm{~nm}$. In spite of the great number of papers dealing with surface phenomena in chalcogenide thin films, the investigations by ellipsometric measurements are still in the beginning.

In the present paper the optical properties of thin films on the base of $\mathrm{As}_{2} \mathrm{~S}_{3}$ and $\mathrm{GeS}_{2}$ as a function of the composition and thickness were investigated by MAI ellipsometry. The optical parameters of the thin films from the previous systems were determined with an accuracy of $0.2-0.3 \%$ for thickness in the range from $\lambda / 20$ to $2 \lambda$. A good agreement was demonstrated between the values of the optical constants as obtained by ellipsometric and spectrophotometric measurements in the case of homogeneous thin films from As-S(Se) and As$\mathrm{S}-\mathrm{Ge}$ systems. The possibility is shown for the refractive index to be varied in wide range from 2.05 to 3.15. The inhomogeneity of thin As-S-Tl(Bi) films leads to discrepancy of the results derived from both types of measurements. The refractive index profile of thin $\mathrm{As}_{38} \mathrm{~S}_{56} \mathrm{Tl}_{6}$ and $\mathrm{As}_{38} \mathrm{~S}_{56} \mathrm{Bi}_{6}$ films is investigated. It was found that the variation of the refractive index with the distance from the substrate to the surface was about 0.8 and 0.1 , respectively. This result presents an opportunity for utilization of inhomogeneous layers from As-S-Tl(Bi) system in photonic multilayer structures. The possibility for deposition of homogenous As-S-Tl(Bi, In) layers by coevaporation of $\mathrm{As}_{2} \mathrm{~S}_{3}$ and metal compounds is demonstrated.

\section{Acknowledgment}

The authors would like to acknowledge the financial support from Project BG05PO001-3.3-005/0001 "Science \& Business" branch, operational program "Human Resource Development."

\section{References}

[1] R. V. A. Azzam and N. M. Bashara, Ellipsometry and Polarized Light, chapter 4, North-Holland, Amsterdam, The Netherlands, 1977.

[2] L. Ward, "The accuracy of some mixed photometric and polarimetric functions in the determination of the optical constants of thin films," Journal of Physics D, vol. 17, no. 9, pp. 1781-1790, 1984.

[3] K. Vedam, "Spectroscopic ellipsometry: a historical overview," Thin Solid Films, vol. 313-314, pp. 1-9, 1998.

[4] D. E. Aspnes, "Expanding horizons: new developments in ellipsometry and polarimetry," Thin Solid Films, vol. 455-456, pp. 3-13, 2004.

[5] T. E. Jenkins, "Multiple-angle-of-incidence ellipsometry," Journal of Physics D, vol. 32, no. 9, pp. R45-R56, 1999.

[6] D. E. Aspnes and A. A. Studna, "Dielectric functions and optical parameters of $\mathrm{Si}, \mathrm{Ge}, \mathrm{GaP}, \mathrm{GaAs}, \mathrm{GaSb}$, InP, InAs, and InSb from 1.5 to 6.0 eV," Physical Review B, vol. 27, no. 2, pp. 985-1009, 1983.

[7] A. Zakery and S. R. Elliott, "Optical properties and applications of chalcogenide glasses: a review," Journal of Non-Crystalline Solids, vol. 330, no. 1-3, pp. 1-12, 2003.

[8] B. F. Bowden and J. A. Harrington, "Fabrication and characterization of chalcogenide glass for hollow Bragg fibers," Applied Optics, vol. 48, no. 16, pp. 3050-3054, 2009.

[9] E. Márquez, J. M. González-Leal, A. M. Bernal-Oliva, T. Wagner, and R. Jiménez-Garay, "Preparation and optical dispersion and absorption of Ag-photodoped $\mathrm{Ge}_{x} \mathrm{Sb}_{40-x} \mathrm{~S}_{60}(x \leq 10,20$ and 30) chalcogenide glass thin films," Journal of Physics $D$, vol. 40, no. 17 , pp. 5351-5357, 2007.

[10] N. Terakado and K. Tanaka, "Photo-induced phenomena in $\mathrm{GeO}_{2}-\mathrm{GeS}_{2}$ glasses," Japanese Journal of Applied Physics B, vol. 46, no. 12-16, pp. L265-L267, 2007.

[11] K. Petkov and B. Dinev, "Photo-induced changes in the optical properties of amorphous As-Ge-S thin films," Journal of Materials Science, vol. 29, no. 2, pp. 468-472, 1994. 
[12] J. Tasseva, K. Petkov, D. Kozhuharova, and T. Iliev, "Lightinduced changes in the physico-chemical and optical properties of thin Ge-S-Se-As films," Journal of Optoelectronics and Advanced Materials, vol. 7, no. 3, pp. 1287-1292, 2005.

[13] C. Tsay, Y. Zha, and C. B. Arnold, "Solution-processed chalcogenide glass for integrated single-mode mid-infrared waveguides," Optics Express, vol. 18, no. 25, pp. 26744-26753, 2010.

[14] A. V. Rode, A. Zakery, M. Samoc, R. B. Charters, E. G. Gamaly, and B. Luther-Davies, "Laser-deposited $\mathrm{As}_{2} \mathrm{~S}_{3}$ chalcogenide films for waveguide applications," Applied Surface Science, vol. 197-198, pp. 481-485, 2002.

[15] X. H. Zhang, L. Calvez, V. Seznec et al., "Infrared transmitting glasses and glass-ceramics," Journal of Non-Crystalline Solids, vol. 352, no. 23-25, pp. 2411-2415, 2006.

[16] K. Suzuki, Y. Hamachi, and T. Baba, "Fabrication and characterization of chalcogenide glass photonic crystal waveguides," Optics Express, vol. 17, no. 25, pp. 22393-22400, 2009.

[17] J. M. Laniel, N. Hô, R. Vallée, and A. Villeneuve, "Nonlinearrefractive-index measurement in $\mathrm{As}_{2} \mathrm{~S}_{3}$ channel waveguides by asymmetric self-phase modulation," Journal of the Optical Society of America B, vol. 22, no. 2, pp. 437-445, 2005.

[18] K. Ogusu, J. Yamasaki, S. Maeda, M. Kitao, and M. Minakata, "Linear and nonlinear optical properties of Ag-As-Se chalcogenide glasses for all-optical switching," Optics Letters, vol. 29, no. 3, pp. 265-267, 2004.

[19] A. Andriesh, "Chalcogenide glasses as multifunctional photonic MATERIALS," Journal of Optoelectronics and Advanced Materials, vol. 7, no. 6, pp. 2931-2939, 2005.

[20] T. Wágner and P. J. S. Ewen, "Photo-induced dissolution effect in $\mathrm{Ag} / \mathrm{As}_{33} \mathrm{~S}_{67}$ multilayer structures and its potential application," Journal of Non-Crystalline Solids, vol. 266-269, pp. 979-984, 2000.

[21] G. Beadie, W. S. Rabinovich, J. Sanghera, and I. Aggarwal, "Fabrication of microlenses in bulk chalcogenide glass," Optics Communications, vol. 152, no. 4-6, pp. 215-220, 1998.

[22] T. Kawaguchi and S. Maruno, "Kinetic study of metallic silver photoinduced surface deposition phenomenon," Japanese Journal of Applied Physics A, vol. 33, no. 6, pp. 3417-3418, 1994.

[23] R. A. Synowicki and T. E. Tiwald, "Optical properties of bulk $\mathrm{c}-\mathrm{ZrO} 2, \mathrm{c}-\mathrm{MgO}$ and $\mathrm{a}-\mathrm{As}_{2} \mathrm{~S}_{3}$ determined by variable angle spectroscopic ellipsometry," Thin Solid Films, vol. 455-456, pp. 248-255, 2004.

[24] D. Franta, I. Ohlídal, M. Frumar, and J. Jedelský, "Optical characterization of chalcogenide thin films," Applied Surface Science, vol. 175-176, pp. 555-561, 2001.

[25] R. Todorov and K. Petkov, "Light induced changes in the optical properties of thin As-S-Ge(Bi, Tl) films," Journal of Optoelectronics and Advanced Materials, vol. 3, no. 2, pp. 311$317,2001$.

[26] R. Todorov, A. Paneva, and K. Petkov, "Optical characterization of thin chalcogenide films by multiple-angle-of-incidence ellipsometry," Thin Solid Films, vol. 518, no. 12, pp. 3280-3288, 2010.

[27] R. Todorov, T. Iliev, and K. Petkov, "Light-induced changes in the optical properties of thin films of $\mathrm{Ge}-\mathrm{S}-\mathrm{Bi}(\mathrm{Tl}, \mathrm{In})$ chalcogenides," Journal of Non-Crystalline Solids, vol. 326-327, pp. 263-267, 2003.

[28] L. F. Santos, A. Ganjoo, H. Jain, and R. M. Almeida, "Optical and spectroscopic characterization of germanium selenide glass films," Journal of Non-Crystalline Solids, vol. 355, no. 37-42, pp. 1984-1988, 2009.
[29] M. V. Sopinskyy, P. E. Shepeliavyi, A. V. Stronski, and E. F. Venger, "Ellipsometry and AFM study of post-deposition transformations in vacuum-evaporated As-S-Se films," Journal of Optoelectronics and Advanced Materials, vol. 7, no. 5, pp. 22552266, 2005.

[30] V. Pamukchieva and A. Szekeres, "Optical properties of $\mathrm{Ge}_{x} \mathrm{Sb}_{20-x} \mathrm{Te}_{80}$ thin films and their changes by light illumination," Optical Materials, vol. 30, no. 7, pp. 1088-1092, 2008.

[31] T. Ide, M. Suzuki, and M. Okada, "Spectroscopic ellipsometry studies on optical constants of $\mathrm{Ge}_{2} \mathrm{Sb}_{2} \mathrm{Te}_{5}$ used for phase change optical disks," Japanese Journal of Applied Physics B, vol. 34, no. 4, pp. L529-L532, 1995.

[32] M. Yaman, H. E. Kondakci, and M. Bayindir, "Large and dynamical tuning of a chalcogenide fabry-perot cavity mode by temperature modulation," Optics Express, vol. 18, no. 3, pp. 3168$3173,2010$.

[33] S. Y. Kim, S. J. Kim, H. Lim et al., "Spectro-ehipsometry investigation of cascaded crystallization behavior of phase-change $\mathrm{Ge}-$ Sb-Te alloy," Japanese Journal of Applied Physics B, vol. 40, no. 3, pp. 1575-1577, 2001.

[34] S. H. Messaddeq, V. K. Tikhomirov, Y. Messaddeq, D. Lezal, and M. Siu Li, "Light-induced relief gratings and a mechanism of metastable light-induced expansion in chalcogenide glasses," Physical Review B, vol. 63, no. 22, Article ID 224203, 5 pages, 2001.

[35] Y. Murakami, T. Ogawa, M. Wakaki, and S. Kawabata, "Insitu ellipsometric observations of thickness change in the layers of $\mathrm{Ag} / \mathrm{a}-\mathrm{As}_{2} \mathrm{~S}_{3}$ film system with progression of photodoping," Japanese Journal of Applied Physics A, vol. 39, no. 2, pp. 509-510, 2000.

[36] V. Pamukchieva, A. Szekeres, and D. Arsova, "Spectroscopic ellipsometry study of the effect of illumination and thermal annealing on the optical constants of thin Ge-As-S films," Physica Scripta, vol. 83, no. 2, Article ID 025405, 2011.

[37] I. Ohlídal, D. Franta, M. Šiler et al., "Comparison of dispersion models in the optical characterization of As-S chalcogenide thin films," Journal of Non-Crystalline Solids, vol. 352, no. 5254, pp. 5633-5641, 2006.

[38] J. Tasseva, R. Todorov, D. Tsankov, and K. Petkov, “Optical properties of multi-component arsenic-containing chalcogenide thin films," Journal of Optoelectronics and Advanced Materials, vol. 9, no. 2, pp. 344-347, 2007.

[39] K. Petkov, T. Iliev, R. Todorov, and D. Tzvetkov, "X-ray microanalysis and optical properties of thin As-S-Bi ( $\mathrm{Tl}$ ) films," Vacuum, vol. 58, no. 2, pp. 321-326, 2000.

[40] L. Tichý, H. Tichá, P. Nagels, and E. Sleeckx, "A review of the specific role of oxygen in irreversible photo- and thermally induced changes of the optical properties of thin film amorphous chalcogenides," Optical Materials, vol. 4, no. 6, pp. 771779, 1995.

[41] C. K. Carniglia, "Ellipsometric calculations for nonabsorbing thin films with linear refractive-index gradients," Journal of Optical Society of America A, vol. 7, no. 5, pp. 848-856, 1990.

[42] D. E. Aspnes, J. B. Theeten, and F. Hottier, "Investigation of effective-medium models of microscopic surface roughness by spectroscopic ellipsometry," Physical Review B, vol. 20, no. 8, pp. 3292-3302, 1979.

[43] G. E. Jellison Jr., "Spectroscopic ellipsometry data analysis: measured versus calculated quantities," Thin Solid Films, vol. 313-314, pp. 33-39, 1998. 
[44] M. K. Smit and J. W. Verhoof, "Accuracy analysis in multiple angle of incidence ellipsometry," Thin Solid Films, vol. 189, no. 2, pp. 193-203, 1990.

[45] R. Swanepoel, "Determination of the thickness and optical constants of amorphous silicon," Journal of Physics E, vol. 16, no. 12, pp. 1214-1222, 1983.

[46] R. Todorov, D. Tsankov, J. Pirov, and K. Petkov, "Structure and optical properties of thin $\mathrm{As}_{2} \mathrm{~S}_{3}-\mathrm{In}_{2} \mathrm{~S}_{3}$ films," Journal of Physics D, vol. 44, no. 30, Article ID 305401, 2011.

[47] K. Petkov, G. Vassilev, R. Todorov, J. Tasseva, and V. Vassilev, "Optical properties and structure of thin films from the system $\mathrm{GeSe}_{2}-\mathrm{Sb}_{2} \mathrm{Se}_{3}$-AgI," Journal of Non-Crystalline Solids, vol. 357, no. 14, pp. 2669-2674, 2011.

[48] K. Tanaka, "Optical properties and photo-induced changes in amorphous As-S films," Thin Solid Films, vol. 66, no. 3, pp. 271279,1980 .

[49] M. I. Kozak, V. N. Zhikharev, V. Y. Loya, I. P. Studenyak, I. I. Shpak, and I. I. Turok, "An ellipsometric study of relaxationinduced changes in the optical characteristics and structural inhomogeneity of $\mathrm{As}_{2} \mathrm{~S}_{3}$ glassy thin films," Technical Physics Letters, vol. 32, no. 5, pp. 456-458, 2006.

[50] J. Tasseva, R. Todorov, and K. Petkov, "Linear and non-linear optical properties of thin films from the system As-S-Se," Journal of Optoelectronics and Advanced Materials, vol. 11, no. 9, pp. 1257-1260, 2009.

[51] E. Vateva, D. Arsova, E. Skordeva, and V. Pamukchieva, "Irreversible and reversible changes in band gap and volume of chalcogenide films," Journal of Non-Crystalline Solids, vol. 326327, pp. 243-247, 2003.

[52] R. Todorov, J. Tasseva, T. Babeva, and K. Petkov, "Multilayer $\mathrm{As}_{2} \mathrm{Se}_{3} / \mathrm{GeS}_{2}$ quarter wave structures for photonic applications," Journal of Physics D, vol. 43, no. 50, Article ID 505103, 8 pages, 2010.

[53] F. Abelès and M. L. Thèye, "Méthode de calcul des constantes optiques des couches minces absorbantes à partir de mesures de réflexion et de transmission," Surface Science, vol. 5, no. 3, pp. 325-331, 1966.

[54] I. Chambouleyron, S. D. Ventura, E. G. Birgin, and J. M. Martínez, "Optical constants and thickness determination of very thin amorphous semiconductor films," Journal of Applied Physics, vol. 92, no. 6, pp. 3093-3102, 2002.

[55] R. Andrade, E. G. Birgin, I. Chambouleyron, J. M. Martinez, and S. D. Ventura, "Estimation of the thickness and the optical parameters of several stacked thin films using optimization," Applied Optics, vol. 47, no. 28, pp. 5208-5220, 2008.

[56] T. P. Martin, "Stability of As-S clusters," The Journal of Chemical Physics, vol. 80, no. 1, pp. 170-175, 1984.

[57] K. Petkov, R. Todorov, D. Kozhuharova, L. Tichy, E. Cernoskova, and P. J. S. Ewen, "Changes in the physicochemical and optical properties of chalcogenide thin films from the systems As-S and As-S-Tl," Journal of Materials Science, vol. 39, no. 3, pp. 961968, 2004.

[58] F. L. McCrackin and J. P. Colson, "Computational techniques for the use of the exact drude equations in reflection problems," in Ellipsometry in the Measurement of Surfaces and Thin Films, E. Passaglia, R. R. Stromberg, and J. Kruger, Eds., National Bureau of Standards Miscellaneous Publication 256, pp. 61-82, National Bureau of Standards, Washigton, DC, USA, 1964.

[59] R. Swanepoel, "Determination of surface roughness and optical constants of inhomogeneous amorphous silicon films," Journal of Physics E, vol. 17, no. 10, pp. 896-903, 1984.
[60] O. S. Heavens, Optical Properties of Thin Solid Films, Butterworth Scientific, London, UK, 1955.

[61] J. P. Borgogno, B. Lazarides, and E. Pelletier, "Automatic determination of the optical constants of inhomogeneous thin films," Applied Optics, vol. 21, no. 22, pp. 4020-4029, 1982.

[62] S. Chattopadhyay, Y. F. Huang, Y. J. Jen, A. Ganguly, K. H. Chen, and L. C. Chen, "Anti-reflecting and photonic nanostructures," Materials Science and Engineering R, vol. 69, no. 1-3, pp. 1-35, 2010.

[63] A. Lalova and R. Todorov, "Optical properties of porous chalcogenide films for sensor application," Journal of Physics: Conference Series, vol. 398, no. 1, Article ID 012023, 2012.

[64] J. Tasseva, R. Todorov, T. Babeva, and K. Petkov, "Structural and optical characterization of Ag photo-doped thin $\mathrm{As}_{40} \mathrm{~S}_{60-x} \mathrm{Se}_{x}$ films for non-linear applications," Journal of Optics, vol. 12, no. 6, Article ID 065601, 2010. 

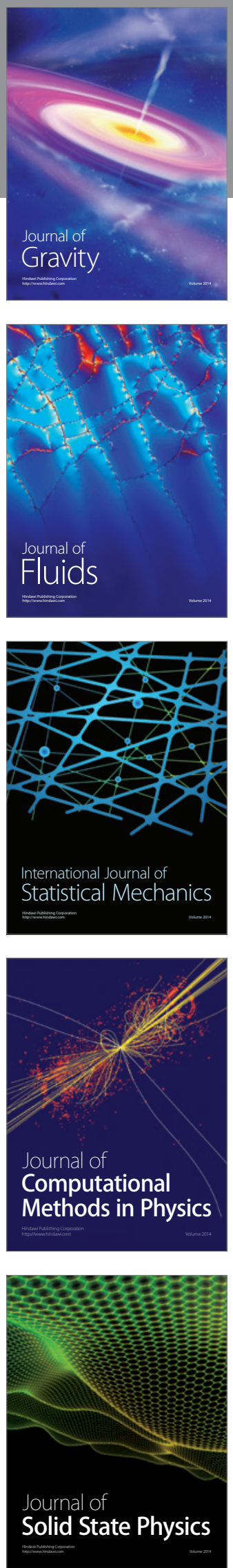

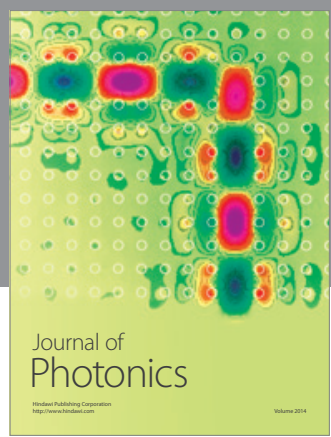

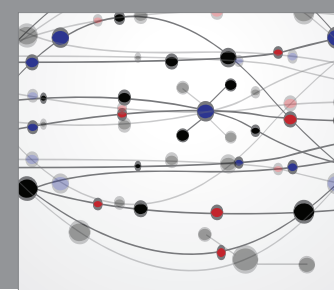

The Scientific World Journal

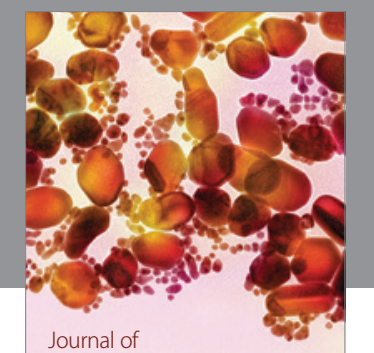

Soft Matter
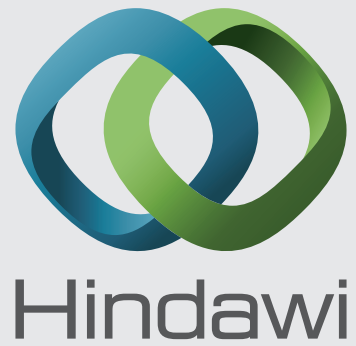

Submit your manuscripts at

http://www.hindawi.com
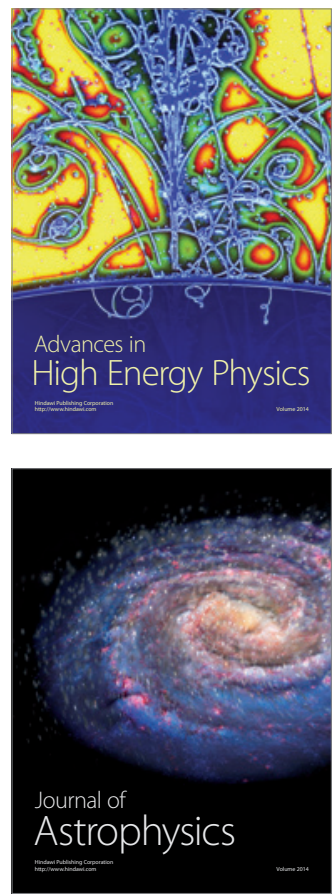
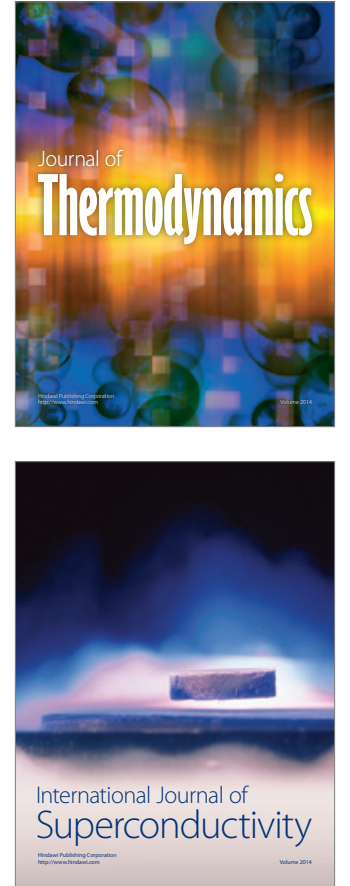
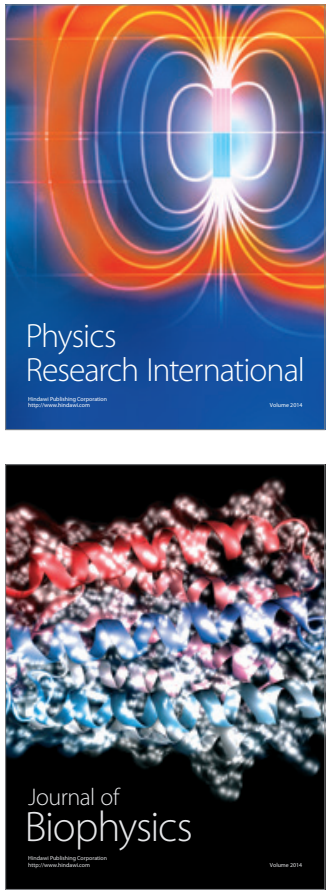
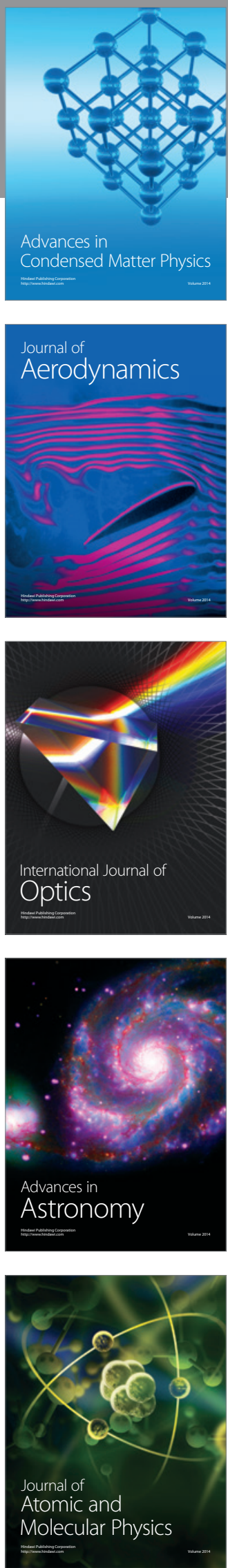